\title{
The Effect of Zinc-Deficient Pregnant Albino Rats on the Retinal Development of their Embryos and Offspring: Light Microscopic and Immunohistochemical Study
}

\author{
REFAAT S. MOHAMED, M.D.; SAYED A. SAYED, M.D.; HEBA K. MOHAMED, M.D. and \\ NOHA A. RASHED, M.Sc.
}

The Department of Anatomy \& Embryology*, Faculty of Medicine, Assiut University, Assiut, Egypt

\begin{abstract}
Background: Zinc is involved in many biochemical functions. Over 300 enzymes require zinc for their activation and nearly 2000 transcription factors require zinc for gene expression. Zinc is also an effective antioxidant and anti-inflammatory agent. Nutritional deficiency of zinc may affect nearly 2 billion subjects in the developing world.
\end{abstract}

Aim of Study: Because of the prevalence of malnutrition throughout the world this study was carried out to detect the possible effects of zinc-deficient pregnant albino rats on the retinal development of their embryos and offspring.

Material and Methods: Female rats after mating were randomly divided into 2 equal groups: One control group received single intraperitoneal injection of distilled water on day 9 of gestation and one experimental group received intraperitoneal injections of 1.10 phenanthroline (zinc chelator purchased from Sigma Company), in a single dose of 30 $\mathrm{mg} / \mathrm{kg}$ on day 9 of gestation. From the embryos and offspring of both control and treated mothers (at the following prenatal gestational days: $13,15,17,19$ and the following postnatal days: (newborn, 7 days, 15 days and 21 days), retinal specimens were processed for Haematoxylin \& Eosin staining technique and immunohistochemical study using caspase- 3 antibody was used to detect apoptosis in the postnatal age groups.

Results: The light microscopic study of the 13 days zinc deficient embryo retina showed apparent shrinkage of the lens vesicle and the optic cup was well formed but it appeared to be shrunken. The retinal pigment epithelium (RPE) of $15^{\text {th }}$, $17 \mathrm{t}$ and $19 \mathrm{t}$ day old zinc-deficient embryos consistently contained apoptotic cells with vacuolated cytoplasm and rarified nuclei. The neuroblastic layer showed apparent decrease in thickness and less mitotic features. The ganglion cell layer revealed numerous deeply stained pyknotic nuclei in the 19th gestational day. Retinae of the newborn, 7 days, 15 days, 21 days-old zinc deficient albino rats showed that the (RPE) contained some vacuolated cells with pyknotic nuclei. The organization of the retina was altered in zinc deficient rats. In addition, apparent reduction in the total retinal thickness and degenerative changes in some layers

Correspondence to: Dr. Noha A. Rashed, E-Mail: noharashed2006@gmail.com. were observed. By the immunohistochemical study, there was intense positive caspase- 3 reaction in all layers of the treated rat retina.

Conclusion: This study revealed that zinc has a role in the developing rat retina and its deficiency causes cytoarchitectural and maturational changes in the retina of the albino rats. These histological changes may impair the visual functions of the retina; so it is recommended that further investigations should be carried out to determine the relevancy of deprivation of zinc as an etiologic factor in the development of retinal degeneration.

Key Words: Retina - Zinc deficiency - Prenatal development - Postnatal development - Albino rat.

\section{Introduction}

THE retina is derived from the two layers of the invaginated optic vesicle. The outer layer becomes a stratum of cuboidal pigment cells that separates the choroid from the neural retina, and therefore forms the outermost layer of the retina (the retinal pigment epithelium). The other nine strata of the retina develop from the inner layer of the optic vesicle and form the neural retina [1]

The body does not have storage of zinc. Approximately $1 \%$ of the total body zinc needs to be replenished daily with the diet. Long periods of zinc depletion cannot be compensated. Systemic zinc deficiency can result from mutations in the gene encoding the ZIP4-transporter (i.e. acrodermatitis enteropathica), which is important in intestinal uptake, or can be acquired in cases of decreased dietary intake, decreased absorption, increased elimination, tissue and cellular redistribution or use of certain medications (penicillamine, diuretics, antimetabolites, valproate and iron salts) [2]. 
Zinc deficiency appears to have dramatic effects on the eye. The occurrence of sever zinc deficiency in human populations under normal conditions is relatively rare. Marginal zinc deficiency has been reported in large numbers of the population and has not been extensively explored in relation to eye structure and function [3] .

To investigate the possibility of zinc deficiency as one etiologic factor for retinal abnormalities, rats were made zinc deficient by treating them with the zinc chelating agents, dithizone and 1,10phenanthroline, or by feeding them a zinc-deficient diet. In both conditions, there was a dense accumulation of osmophilic inclusion bodies in the retinal pigment epithelium then eventually degeneration of the retinal pigment epithelium and the photoreceptors outer segments [4].

It has been reported that a zinc deficient diet resulted in an "ageing-like" process, with melanosomal morphological changes [5], severe degeneration of the photoreceptor outer segments and osmiophilic inclusion bodies in the RPE, Such alterations are typically found in pigmentary disorders [4].

In this study, because of the prevalence of malnutrition throughout the world, we aimed to investigate the possible histological and immunohistochemical changes that might occur as a result of maternal zinc deficiency on the retinal development of their embryos and offspring.

\section{Patients and Methods}

The experiment was conducted from January 2013 to November 2017 at the Anatomy and Embryology Department, Faculty of Medicine, Assiut University, Egypt.

A total number of 48 adult ( 3 months aged) female and 12 adult male weighing (200-250) gm albino rats were obtained from Animal House, Faculty of Medicine, Assiut University. The animals were housed in a room with a 12:12hr light: Dark cycle and were kept under controlled temperature. Food and water were available ad libitum.

Female rats were mated with male overnight (not more than 4 adult females with one adult male), vaginal smears were taken by inserting a glass rod smoothly into the vagina; smears were spread on a slide and stained by shori stain. The estrus period is characterized by the presence of cornified non nucleated epithelial cells without leucocytes. After appearance of the mucous plug, the vaginal smear of pregnant rats was found to contain cornified non nucleated epithelial cells, leucocytes and large quantity of mucous [6]. This experiment was accomplished with known guidelines of animal ethics committee, which were established in accordance with the internationally accepted principles for laboratory animal's use and care.

\section{Experimental protocol and age groups:}

Pregnant female rats were singly housed and randomly were divided into 2 groups: One control group and one experimental group.

Group A (Control): A total number of 24 adult pregnant female rats received single intraperitoneal injection of distilled water on day 9 of gestation.

Group B (Experimental): A total number of 24 adult female rats received intraperitoneal injection of 1.10 phenanthroline in a single dose of $30 \mathrm{mg} / \mathrm{kg}$ on day 9 of gestation (1.10 phenanthroline is a zinc chelator reported to temporary decrease the zinc level in the body during this critical period of higher metal requirments of fetuses. It is purchased as powder from Sigma Company, utilized as aqueous preparation in a ratio of $3 \mathrm{mg} / \mathrm{ml}$ of distilled water and it was used because of its availability and low cost). The used drug and the dose in this work were according to [7].

The occurrence of zinc deficiency was confirmed by measuring the serum zinc level in both groups of pregnant female rats on the 10 th day of gestation. It was measured by standard atomic absorption technique in Clinical Toxicology and Forensic Chemistry Laboratory, Faculty of Medicine, Assiut University.

Embryos and offspring of the treated and control rats were sacrificed at the following prenatal ages: 13 th, 15 th, 17 th and 19 th days of gestation and the following postnatal ages: Newborn, 7 days, 15 days and 21 days. Ages that were chosen for the prenatal study were the ages of thirteenth, fifteenth; seventeenth and nineteenth days of gestation. This is the period of the beginning of development of retina as documented by [8]. Postnatally, newborn, seven days, fifteen days, twenty-one days ages were chosen as that is the period of lactation as weaning occur on the twenty first day, according to [9]. These postnatal ages were chosen to detect the effect of the lactation of milk of zinc deficient mothers on the retina of the offspring.

From the embryos and offspring of both control and treated mothers, 3 rats were used in each of the studied age groups for Haematoxylin \& Eosin 
staining technique to study the cytoarchitectural and maturational changes in the retina. Immunohistochemical study using caspase- 3 was used for the newborn, 7 days, 15 days and 21 days postnatal age groups.

In the prenatal study: Pregnant rats were anaesthetized by ether inhalation and rat fetuses were extracted, fixed in Bouin's fixative. For the 13 th day of gestation, the embryos were used with the membranes and for the 15 th, 17 th and 19th days of gestation embryos were used without membranes but the heads were used only. The embryos and the heads were cut serially in the sagittal plane and processed for paraffin sectioning

In the postnatal study: The animals were anaesthetized by ether inhalation. The rats were perfused in the left ventricle by normal saline followed by Bouin's fluid. The eyes were enucleated by cutting the conjunctiva near the conjunctivo-scleral junction. Traction of the eyeball was gently done to facilitate the cutting of the optic nerve. Eye balls were put in Bouin's fixative solution. It is preferable to introduce one or two drops of Bouin in the eyeball by very fine needle introduced obliquely in the sclera, thus the Bouin reach directly and immediately into the retina. Bouin's fixative was used as it penetrates rapidly the specimen and causes little shrinkage.

For both prenatal and postnatal specimens the following steps were done:

Samples from each group after fixation were dehydrated, and processed for paraffin blocks. Subsequently, 5-gm-thick sections were cut and stained with hematoxylin and eosin (H\&E) then they were preceded for light microscopic examination according to $[10]$.

\section{Preperation for Immunohistochemical study:}

Immunohistochemical detection of caspase-3 was performed according to [11]; to demonstrate apoptosis; using primary rabbit anti-rat caspase3 antibody from (Thermo Scientific Company, USA). After fixation in $10 \%$ neutral-buffered formalin for 2 days, retinal specimens of the control and treated postnatal age groups were dehydrated, cleared and embedded in paraffin. Paraffin sections were cut at $5 \mu \mathrm{m}$ and mounted on coated slides. The slides were treated with $0,01 \mathrm{~mol} / 1$ citrate buffer (pH 6.0) for 10 minutes to unmask antigen. The sections were incubated in $0.3 \% \mathrm{H}_{2} \mathrm{O}_{2}$ for $30 \mathrm{~min}$ to eliminate endogenous peroxidase activity before blocking with $5 \%$ hordes serum for 2 hours at room temperature to inhibit the non specific immunoreactions. Slides were incubated with the primary antibody 1:100 polyclonal rabbit anti-caspase 3 at $4^{\circ} \mathrm{c}$ for 18-20 hour, washed and incubated with biotinylated secondary antibodies and then with the $0.05 \%$ diaminobenzidine. The slides were then counterstained with Myer's haematoxylin, dehydrated, cleared and mounted.

\section{Results}

\section{A- Histological results: \\ I- Prenatal Period: \\ 13 days old embryo of the control group:}

At the age of 13 days old control rat, the lens vesicle was invaginated from the surface ectoderm and appeared to be nearly separated from it. The optic cup was well formed and it appeared to be consisted of an outer (external) wall and an inner (inverted) wall separated by optic ventricle. The external layer of the optic cup (the future pigment epithelium) was formed of tall columnar cells with large oval nuclei. The cells of the inverted wall formed the neuroblastic cell layer which consisted of several layers of columnar cells with indistinct borders and large oval nuclei. Numerous mitotic figures were seen in the external layer of the optic cup and in the outer surface of the inverted layer (neuroblastic cell layer) near the optic ventricle. Elements of hyloid system were seen on the surface of the lens vesicle and within the antrum of the optic cup (Fig. 1).

\section{5 days old embryo of the control group:}

By day 15 of gestation, the lens vesicle was separated from the surface ectoderm. The pigmented epithelial layer of the retina was present as an uneven, single layer of nearly cuboidal cells with round nuclei. Mitosis was scarce in this layer. The inverted (neuroblastic) layer was constantly thickened by extensive mitotic activity at its choroidal edge. The main bulk of the nuclei within the neuroblastic layer were oval in shape, however the inner 2 or 3 layers of nuclei became slightly rounded (Fig. 2).

\section{7 days old embryos of the control group:}

At the embryonic day 17, the retinal pigment epithelium was formed of a single layer of low columnar cells with rounded nuclei. The neuroblastic layer increased in thickness in comparison with the previous age due to the presence of the mitotic figures at the choroidal edge. This layer consisted of two parts: An outer part with condensed dark nuclei and inner part of uncondensed paler nuclei. The pale round nuclei at the inner border of the neuroblastic layer will be the future ganglion cells. The central processes of these rounded cells 
formed a distinct nerve fiber layer. Elements of hyaloid system were numerous in the vitreal cavity (Fig. 3).

\section{9 days old embryos of the control group:}

By the day 19 of gestation, the pigment epithelial layer is well formed. The inner plexiform layer appeared as a relatively clear zone separating between the oval darkly stained nuclei of the neuroblastic layer and the round lighter stained ganglion cell nuclei. The inner plexiform layer contained migrating nuclei within it. The neuroblastic layer showed apparent increase in thickness when compared with the previous age. The ganglion cells layer was formed of 4 to 5 layers of loosely arranged cells. Numerous mitotic cells were noticed at the choroidal edge of the neuroblastic layer. The nerve fiber layer was detected and elements of the hyaloid system were present. The internal limiting membrane was visible (Fig. 4).

\section{3 days old embryo of the experimental group:}

At the age of 13 days old zinc deficient rat embryo, the lens vesicle was invaginated from the surface ectoderm and appeared nearly separated from it. The optic cup was well formed but it appeared to be shrunken as compared with the control group. The external layer of the optic cup contained one cell layer of tall columnar cells with darkly stained nuclei. The inverted layer of the optic cup consisted of several layers of columnar cells with deeply stained pyknotic nuclei. No mitotic figures could be observed. Elements of the hyaloid system were present (Fig. 5).

\section{5 days old embryo of the experimental group:}

At the age of 15 days old rat embryo of group $\mathrm{B}$, the pigmented epithelial layer of the retina was formed of a single layer of roughly cuboidal cells with flat pyknotic nuclei. Some cells appeared vacuolated with rarified nuclei. The neuroblastic layer showed apparent decrease in thickness in comparison with the control group. Most of the nuclei within the neuroblastic layer were oval in shape, but the inner 2 or 3 layers of nuclei were rounded. The nerve fiber layer could be observed (Fig. 6).

\section{7 days old embryos of the experimental group:}

At the age of 17 day old embryo of group B, the retinal pigment epithelium contained small pyknotic nuclei, other cells appeared vacuolated with rarified nuclei. The neuroblastic layer showed less mitotic features. It contained several layers of paler round nuclei at its inner border so the neuroblastic layer appeared to be formed of two parts: outer dark part and inner paler part. The pale rounded cells are suggested to become the future ganglion cells. Elements of hyaloid system were present (Fig. 7).

\section{9 days old embryos of the experimental group:}

In 19 days old embryo of the zinc deficient rat, the pigment epithelial layer consisted of low cuboidal cells arranged in a single layer. The neuroblastic cell layer contained oval darkly stained nuclei and showed apparent decrease in thickness when compared with the control group. The inner plexiform layer separated the ganglion cells layer from the neuroblastic cell layer and contained migrating nuclei within it. The ganglion cell layer revealed numerous deeply stained pyknotic nuclei as compared with the control group. The nerve fiber layer was present. Elements of the hyaloid system were noticed in the vitreal cavity (Fig. 8).

\section{II- Postnatal Period:}

New-born albino rat of the control group:

By light microscopy, the newborn control rat retina consisted of the pigment epithelium and the neuroblastic layer which was formed of two parts, an outer darkly stained compact part and an inner and less compact part with paler nuclei. Mitotic figures were common with considerable increase in the thickness of the neuroblastic layer. The nuclei of the neuroblastic layer remain dark and oval but have become less tightly packed close to the inner plexiform layer. The ganglion cell layer consisted of less condensed paler and more rounded nuclei of well differentiated ganglion cells. The ganglion cell layer showed apparent reduction in thickness when compared with the previous control age group. The inner plexiform layer was distinct and separated between neuroblastic cells and ganglion cells. A few nuclei were scattered within the boundaries of this layer (Fig. 9).

\section{7 days old albino rat of the control group:}

By the 7 th postnatal day, all layers of the retina were present although not in the mature condition. The retinal pigment epithelium was well formed. The inner segment of the photoreceptors started to appear but the outer segment was not developed. The neuroblastic layer was separated by the outer plexiform layer into the outer nuclear layer and the inner nuclear layer. The outer nuclear layer consisted of predominantly oval nuclei which were more compact than those of the inner nuclear layer. This layer was thinner, denser, and more deeply stained than the inner nuclear layer which consisted of less compact nuclei of various sizes and shapes. The cells of the inner nuclear layer began differ- 
entiation into 3 zones of nuclei; an outer zone composed of small dense nuclei, a middle zone containing predominantly oval nuclei and an inner zone of larger, less compact nuclei. The inner plexiform layer became more thickened and separated the inner nuclear layer from the ganglion cell layer which was decreased in thickness to one or two rows of cells when compared with the previous control age group (Fig. 10).

\section{5 days old albino rat of the control group:}

By the $15^{\text {th }}$ postnatal day, all layers of the retina were in the mature condition. The retinal pigment epithelium was well formed. Both the outer and inner segments of the photoreceptors could be easily distinguished. The outer limiting membrane was seen. The outer and inner nuclear layers were both more compact and thinner than the previous control age group. The nuclei of the outer nuclear layer were difficult to delineate because their chromatin tended to form several clumps within each nucleus. The inner nuclear layer appeared thinner and consisted of less compact pale nuclei than the outer nuclear layer and they were separated by the outer plexiform layer which appeared thicker than the previous control age group. The inner plexiform layer became thicker than the previous control age group. The ganglion cell layer was formed of one row of cells. The inner limiting membrane was detected (Fig. 11).

\section{1 days old albino rat of the control group:}

The retina of 21 days old control albino rat resemble the retina of the adult albino rat all layers of the retina were present. The retinal pigment epithelium was well formed. The photoreceptor cell layer was formed of two segments; outer and inner segments; the thick outer segments were lighter in staining compared with the inner segments. The outer limiting membrane was present. The nuclei of the outer nuclear layer were rounded and deeply stained. The outer plexiform layer separated between the outer and inner nuclear layer. The nuclei of the inner nuclear layer were arranged in 4 to 5 layers of nuclei which were larger, paler and less compact than the outer nuclear layer. The inner plexiform layer separated between the inner nuclear and the ganglion cell layer which consisted of closely packed and uniformly distributed large, pale cells arranged in one discontinuous row of ganglion cells. The nerve fiber layer was indistinguishable from the ganglionic cell layer. The internal limiting membrane delineated the internal aspect of the retina (Fig. 12).

\section{New-born albino rat of the experimental group:}

The retina of the newborn rat of the experimental group showed that the retinal pigment epithelium contained some cells appeared vacuolated with pyknotic nuclei. The nuclei of the neuroblastic layer appeared more condensed and smaller in size as compared with the control group. Some cells revealed densely stained pyknotic nuclei. Other cells appeared vacuolated. The inner plexiform layer separated between neuroblastic cells and ganglion cell layer which consisted of well differentiated rounded deeply stained less condensed ganglion cells nuclei. Scanty mitotic figures were noticed. There was apparent reduction in thickness of neural retina when compared with the control group (Fig. 13).

\section{7 days old albino rat of the experimental group:}

In 7 days-old treated albino rat, the retinal pigment epithelium showed some cells with pyknotic nuclei. The inner segments of the photoreceptors were present and revealed vacuolations. The outer plexiform layer separated the neuroblastic layer into outer nuclear layer and inner nuclear layer. The outer nuclear layer was more compact than the inner nuclear layer and appeared more deeply stained and more condensed than the control group. The inner nuclear layer showed apparent reduction in thickness with more densely stained nuclei as compared with those of the control group. The ganglion cells were arranged in one or two rows of deeply stained cells. Many nuclei were densely stained and pyknotic (Fig. 14).

\section{5 days old albino rat of the experimental group:}

In 15 days old treated albino rat, the retinal pigment epithelium, the outer and inner segments of the photoreceptors were present. The outer limiting membrane could not be detected. The nuclei of the outer nuclear layer were deeply stained when compared with the control group. The inner nuclear layer was separated from the outer nuclear layer by the outer plexiform layer and revealed some densely stained nuclei. The inner plexiform layer contained occasional cells and separated the inner nuclear layer from the ganglion cell layer which was formed of one discontinuous row of deeply stained cells. The inner limiting membrane was partially disrupted and undulated (Fig. 15).

\section{1 days old albino rat of the experimental group:}

In 21 days old treated albino rat, the retinal pigment epithelium contained some cells with vacuolated cytoplasm. The outer and inner segments of the photoreceptors were detected but no clear demarcation. Both segments revealed many vacu- 
olations. The outer limiting membrane was hardly observed and appeared disrupted. The nuclei of the outer nuclear layer were more compact and deeply stained nuclei than the control group. $\mathrm{Nu}$ merous deeply stained pyknotic nuclei and vacuolated cytoplasm were noticed in the outer nuclear layer cells. The outer plexiform layer appeared distorted and separated the outer nuclear layer from the inner nuclear layer which appeared condensed with most nuclei were deeply stained and pyknotic when compared with the control group. This layer showed highly dispersed cells with markedly vacuolated cytoplasm. The inner nuclear layer was separated by the inner plexiform layer from the ganglion cell layer which appeared disorganized with some shrunken deeply stained py- knotic nuclei. Ganglion cells exhibited vacuolated degenerated cytoplasm. The inner limiting membrane was disrupted and could be hardly detected (Fig. 16).

\section{Immunohistochemical results:}

By the immunohistochemical study, examination of immunostained retinal sections for caspase3 in the control newborn, 7 days, 15 days, 21 days old rat showed negative expression in all the layers of the retina including the ganglion cells (Figs. 17, $18,19,20$ respectively). While, there was strong positive expression of caspase- 3 in all layers of the retina in the newborn, 7 days, 15 days, 21 days old zinc deficient rats (Figs. 21, 22, 23, 24 respectively).

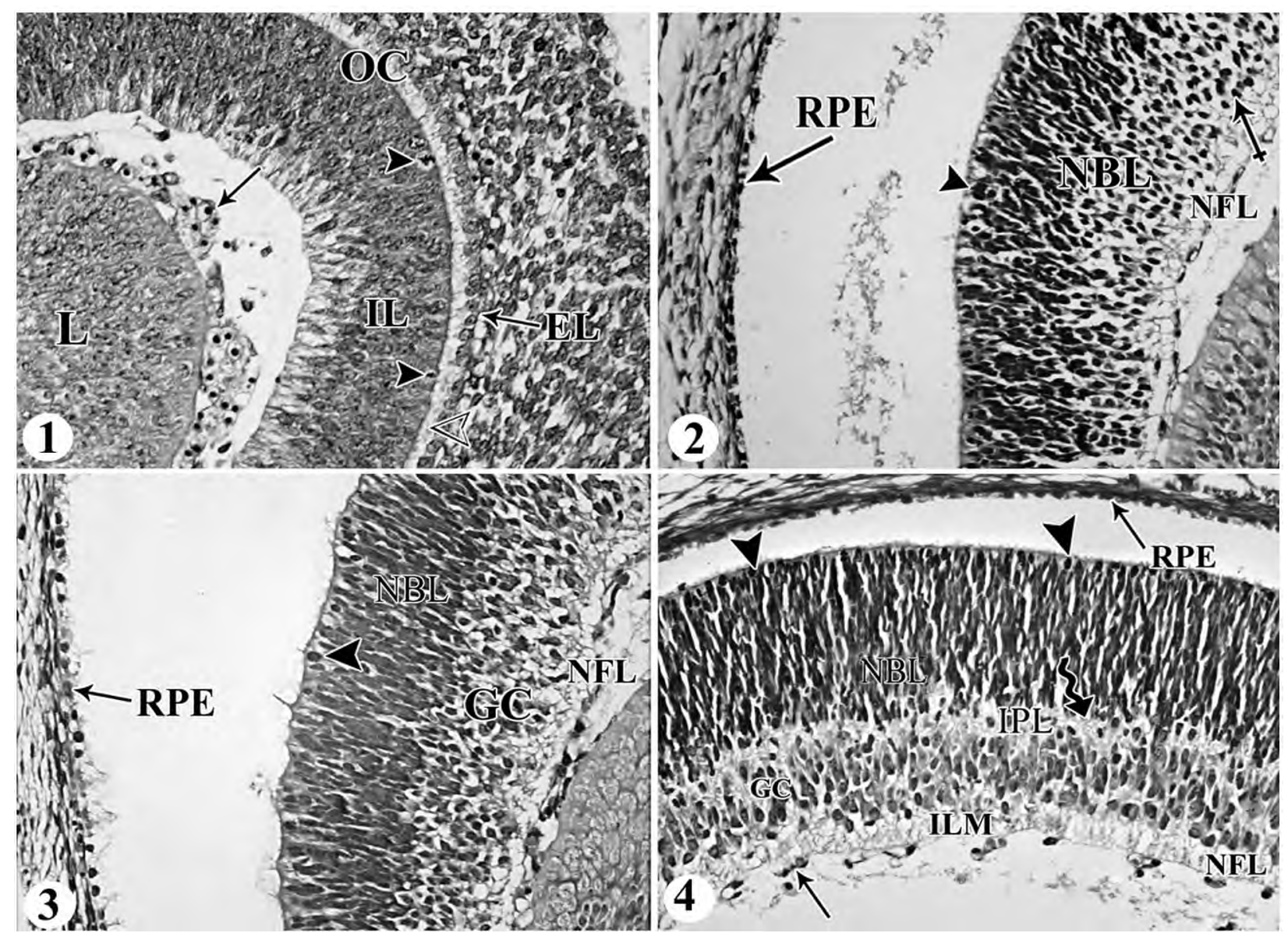

Plate (1): Fig. (1): Photomicrograph of 13 days old embryo eye of the control group showing that the lens vesicle (L), the optic cup (OC) with both its external (EL) and inverted (IL) layers is evident. There are mitotic cells (arrow heads) in the outer surface of the inverted layer (neuroblastic cell layer), near the optic ventricle (open arrow head). Elements of hyaloid system (arrow) are seen. Fig. (2): A photomicrograph of 15 days old embryo retina of the control group showing that the retinal pigment epeithelial layer (RPE), the neuroblastic layer (NBL) which shows increased mitotic activity (arrow head). The outer cells are ovoid while its inner cells are rounded (crossed arrow). The nerve fiber layer (NFL) is observed. Fig. (3): A photomicrograph of the retina of 17 days old embryo from the control group showing that the retinal pigment epithelial layer (RPE). The future ganglion cells (GC) are pale rounded nuclei at the inner border of the neuroblastic layer(NBL). Mitotic figures (arrow head) are present. The nerve fiber layer (NFL) is well formed. Fig. (4): A photomicrograph of the retina of 19 days embryo of the control group showing that the retinal pigment epithelial layer (RPE). The inner plexiform layer (IPL) appears between the neuroblastic layer (NBL) and the ganglion cell nuclei (GC), and it contains migrating nuclei (wavy arrow). The nerve fiber layer (NFL) and the internal limiting membrane (ILM) are visible. Numerous mitotic cells (arrow heads) and elements of the hyaloid system (arrow) are present. (H \& E X 400). 


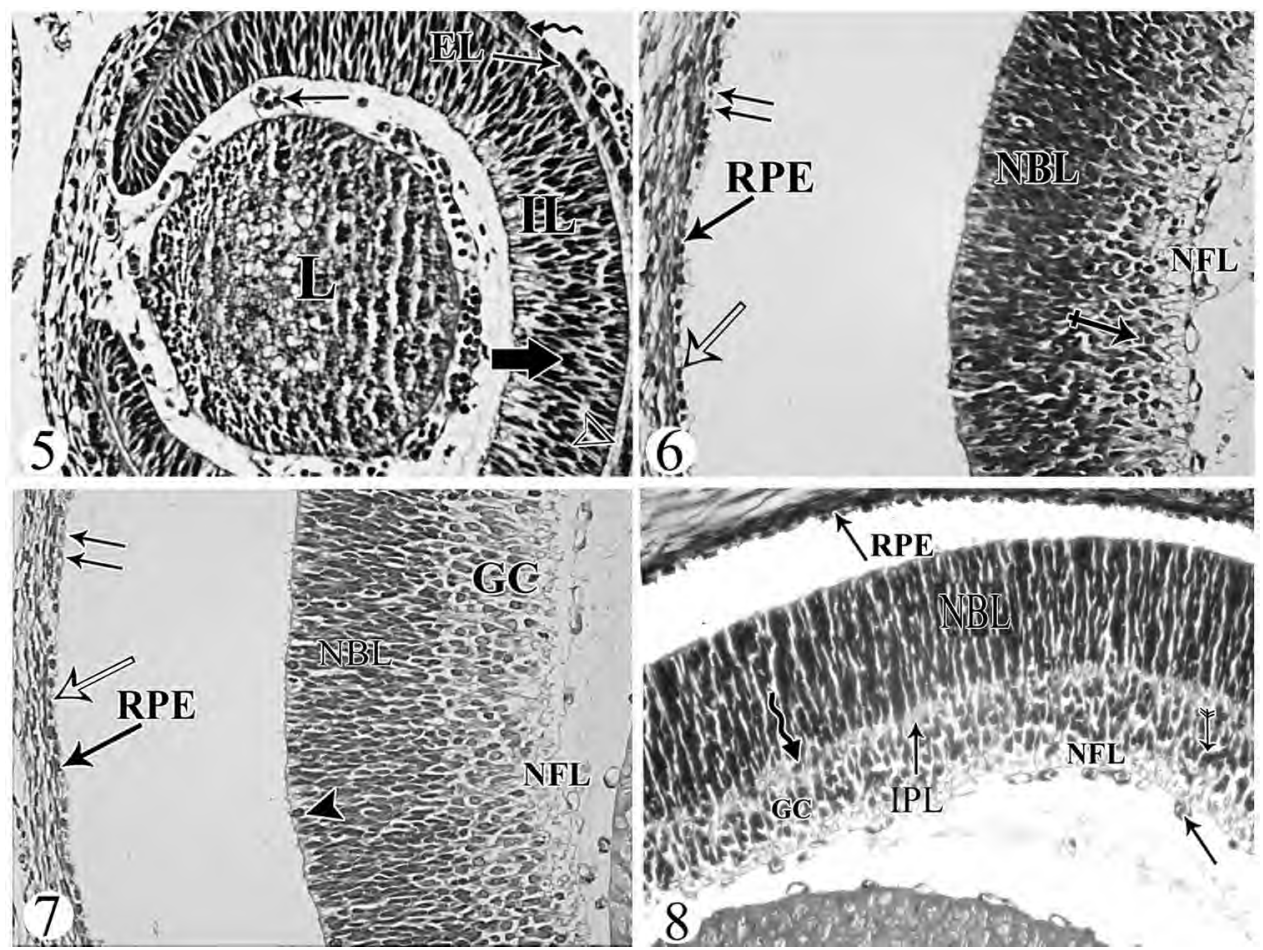

Plate (2): Fig. (5): A photomicrograph of 13 days old embryo eye of the experimental group showing that the lens vesicle (L), the optic cup is formed from external (EL) and inverted layers (IL) which are separated by optic ventricle (open arrow head). The external layer contains darkly stained nuclei (wavy arrow). The inverted layer showed deeply stained pyknotic nuclei (thick arrow). Branches of hyaloid plexus (arrow) are present. Fig. (6): A photomicrograph of the 15 days old embryo retina of the experimental group showing that the retinal pigment epithelial layer (RPE) with flat pyknotic nuclei (open arrow), some cells appear vacuolated with rarified nucleus (double arrow). The inner 2 or 3 layers of the neuroblastic layer (NBL) are nearly rounded (crossed arrow). The nerve fiber layer (NFL) can be noticed. Fig. (7): A photomicrograph of the retina of 17 days old embryo from the experimental group showing that the retinal pigns epishal the future ganglion cells $(\mathrm{GC})$. Less mitotic figures (arrow head) are present. The nerve fiber layer (NFL) is observed. Fig. (Ю: A photomicrograph of the retina of 19 days embryo of the contains migrating nuclei (wavy arrow). The ganglion cell layer reveals numerous deeply stained pyknotic nuclei (tailed arrow). The nerve fiber layer (NFL) and elements of the hyaloid system (arrow) are present. (H \& E X 400).
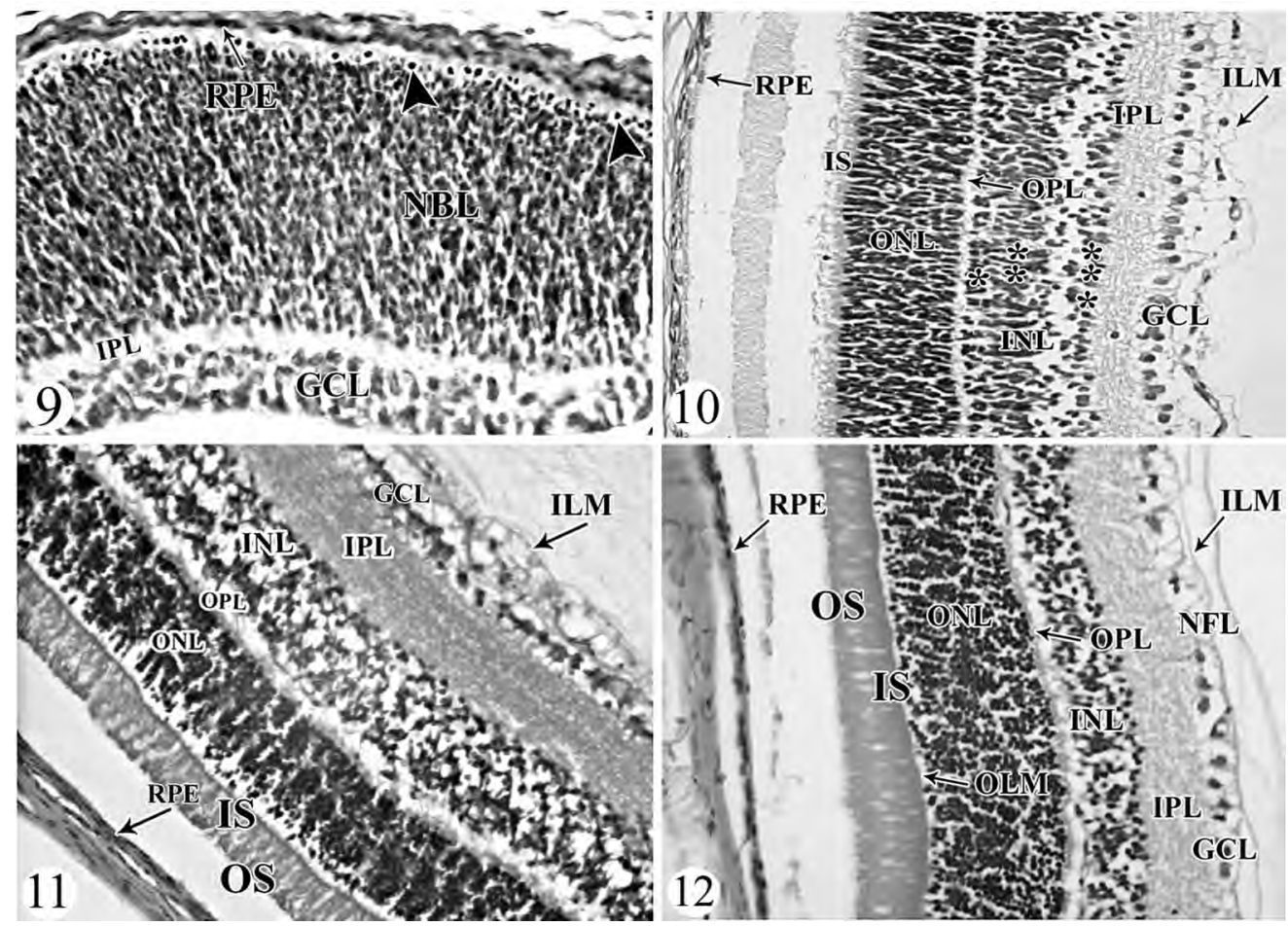

Plate (3): Fig. (9): A photomicrograph of the retina of a new-born control albino rat showing that the retinal pigment epithelium (RPE), the neuroblastic layer (NBL), the ganglion cel layer (GCL), the inner plexiform layer (IPL) are present. Numerous mitotic figures (arrow heads) are common. Fig. (10): A photomicrograph of a section in the retina of 7 days old contro albino rat showing the retinal pigment epithelium (RPE), The inner segment of the photoreceptors (IS) begins to be formed. The outer plexiform layer (OPL) separates between the outer nuclear layer (ONL) and he inner nuclear layer (INL) which revals 3 zones of nucle, an outer nuclear zone (*), a middle zone (*) and an inner zone (**). The inner plexiform layer (IPL), the ganglion cell layer (GCL), the inner limiting membrane (ILM) are detected. Fig. (11): A photomicrograph of the retina of 15 days old control albino rat showing the presence of the retina pigment epithelium (RPE), both the outer (OS) and inner segments (IS) of the photoreceptors, the outer limiting membrane (OLM). The outer nuclear layer (ONL) and the inner nuclear layer photomis photomicrograph of the retina of 21 days old control albino rat showing the retinal pigment epithelium (RPE), the outer segments (OS) and inner segments (IS) of photoreceptorces. The plexiform layer (IPL) from the ganglion cell layer (GCL). The nerve fiber layer (NFL) is indistinguishable from the ganglion cell layer. The internal limiting membrane (ILM) is present (H \& E X 400). 

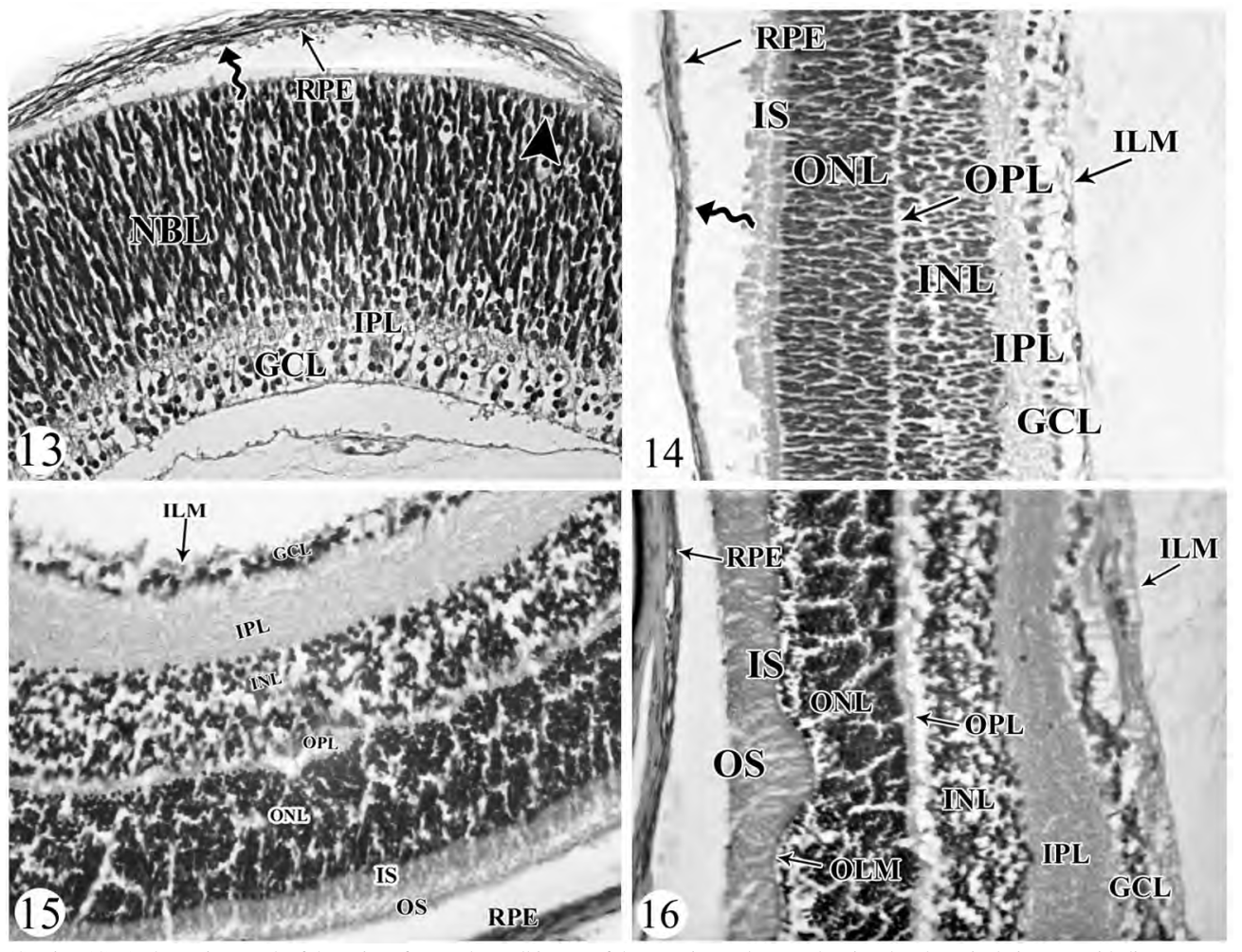

Plate (4): Fig. (13): A photomicrograph of the retina of a new-born albino rat of the experimental group showing that the retinal pigment epithelium (RPE) with some cells appear vacuolated with pyknotic nuclei (wavy arrow). The inner plexiform layer (IPL) separates between neuroblastic layer (NBL) and ganglion cell layer (GCL). Scanty mitotic figures (arrow head) are noticed. Fig. (14): A photomicrograph of the retina of 7 days old experimental albino rat retinashowing that the retinal pigment epithelium (RPE) with some pyknotic nuclei (wavy arrow), the inner segment of the photoreceptors (IS). The outer plexiform layer (OPL) separats between the outer nuclear layer (ONL) and the inner nuclear layer (INL) which in turn is separated from the ganglion cell layer (GCL) by the inner plexiform layer (IPL). The inner limiting membrane (ILM) is present. Fig. (15): A photomicrograph of the retina of 15 days old experimental albino rat retina showing that the retinal pigment epithelium (RPE), the outer segments (OS) and inner segments (IS) of the photoreceptors are present. The inner nuclear layer (INL) is separated from the outer nuclear layer(ONL) by the outer plexiform layer (OPL). The inner plexiform layer (IPL) separates the inner nuclear layer from the ganglion cell layer (GCL). Undulation of the partially disrupted inner limiting membrane (ILM) is noticed. Fig. (16): A photomicrograph of the retina of 21 days old experimental albino rat showing that the retinal pigment epithelium (RPE), the outer segments (OS) and inner segments (IS) of the photoreceptors. The outer nuclear layer (ONL) is separated from the inner nuclear layer (INL) by the outer plexiform layer (OPL). The inner plexiform layer (IPL) is noticed. The ganglion cell layer (GCL) appears disorganized. The inner limiting membrane (ILM) is present (H \& E X 400)
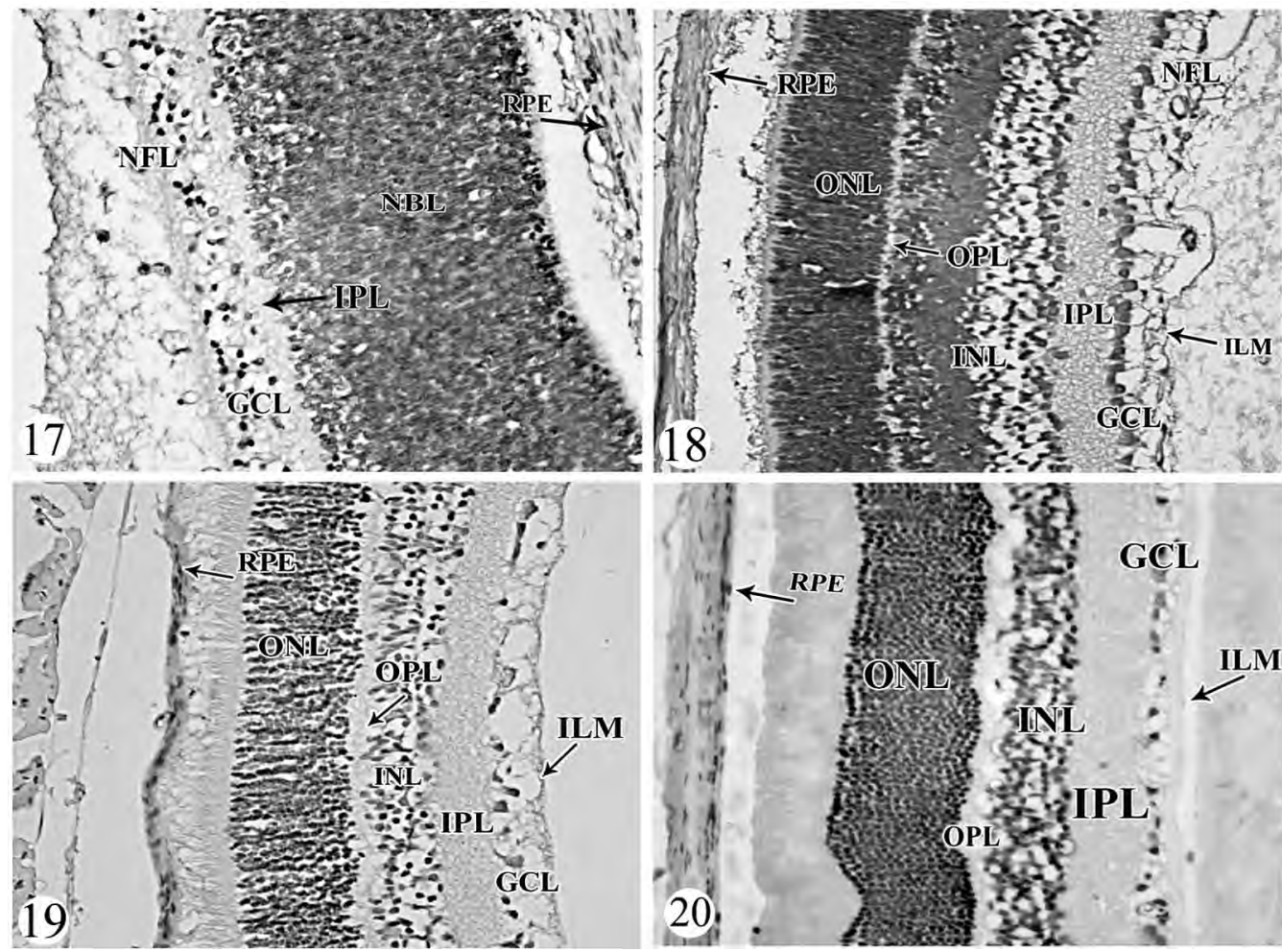

Plate (5): Fig. (17): A photomicrograph of caspase-3 immunostained paraffin section in the retina of new-born control albino rat. Fig. (18):A photomicrograph of caspase-3 imm: retina of 15 days old control albino rat. Fig. (20): A photomicrograph of caspase-3 immunostained paraffin section in the retina of 21 days old control albino rat. All of them show negative immunoreactivity of caspase- 3 in all the layers of retina (X 400). 

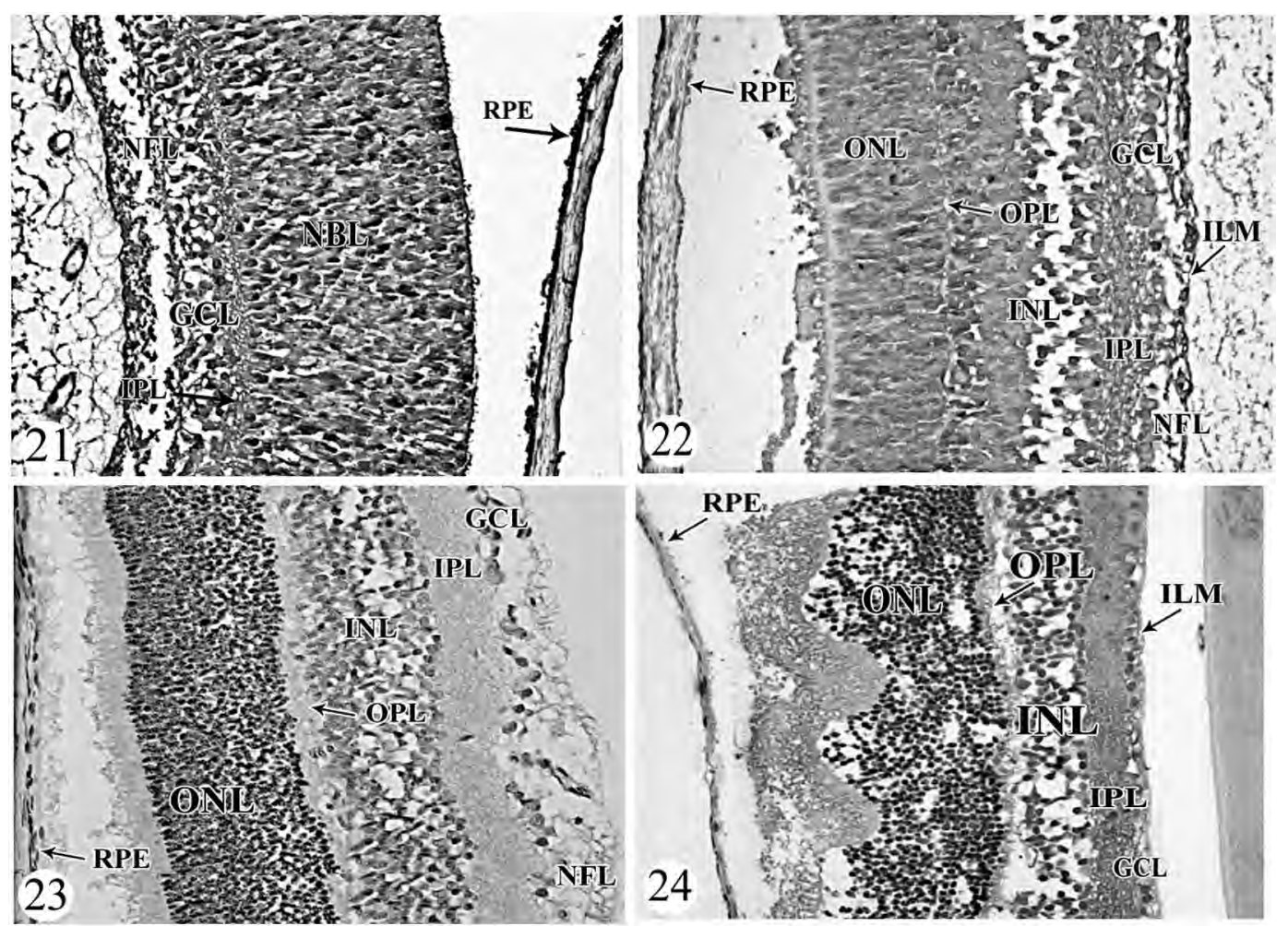

Plate (6): Fig. (21): A photomicrograph of caspase-3 immunostained paraffin section in the retina of a new-born albino rat of the experimental group. Fig. (22): A photomicrograph of caspase- 3 immunostained paraffin section in the retina of 7 days old experimental albino rat. Fig. (23): A photomicrograph of caspase-3 immunostained paraffin section in the retina of 15 days old experimental albino rat. Fig. (24): A photomicrograph of caspase-3 immunostained paraffin section in the retina of 21 days old experimental albino rat. All of them show intense positive reaction of caspase-3 in all retinal layers (X 400).

\section{Discussion}

Vertebrate eyes are based on a common structural plan. Despite differences in embryological development and optical layouts among invertebrates, visual pigment genes are all descended from the same remote ancestor. Furthermore, genes involved in formation of the vertebrate eye have proved to be homologous with those of Drosophila eye [12].

The present study demonstrated that the retina was derived from the two layers of the invaginated optic vesicle. The outer layer becomes a stratum of cuboidal pigment cells that separates the choroid from the neural retina and therefore forms the outermost layer of the retina (the retinal pigment epithelium). The other nine strata of the retina developed from the inner layer of the optic vesicle and formed the neural retina. These findings are in accordance with previous study [1]

The results of the control group examination demonstrated that; at the gestational age of 13 days old rat embryo, the optic cup was well formed and it consisted of an external wall and an inverted wall. By day 15 of gestation, the pigmented epithelial layer of the retina was present and the neuroblastic layer was constantly thickened by extensive mitotic activity. At the embryonic day 17, the neuroblastic layer consisted of two parts: Outer and inner parts. By the day 19 of gestation, the inner plexiform layer separated between the neuroblastic layer and the ganglion cell nuclei. The newborn rat neuroblastic layer was formed of an outer part and an inner part. At the 7 th postnatal day; the inner segment of the photoreceptors started to appear and the outer plexiform layer separated the outer and inner nuclear layers. By 15 days old, retina revealed that all layers of the retina were in the mature condition. These findings are in accordance with the previous work done by [8]. The retina of 21 days old control albino rat resembles the retina of the adult albino rat. Similar light microscopic findings of juvenile rat retina are described by previous research [13].

In this study, there was negative caspase- 3 reaction in all the layers of the control rat retina, these findings are in agreement with [14] who reported that examination of immunostained sections for caspase- 3 showed no expression in all retinal layers including the ganglion cells in the control group.

For optimal growth and survival of the neonate, the dietary requirement for zinc for the pregnant and lactating rat has been estimated to be on the 
order of $25 \mathrm{mg} / \mathrm{kg}$, even when a high-quality protein such as egg white is used. An increased requirement for dietary zinc during pregnancy is also supported by the observation of many investigators who added that, at term, fetal weight and fetal zinc concentrations were higher in litters from dams given water containing $25 \mathrm{mg} \mathrm{Zn} / \mathrm{L}$ compared to dams given water containing $11 \mathrm{mgZn} / \mathrm{L}$ [15] .

The studies done earlier noted that 1,10 phenanthroline causes $13.0 \%$ incidence of soft tissue anomalies when given on gestational day 9 , meanwhile no significant differences in the incidence of skeletal and soft tissue anomalies were reported when it was given on gestational days 10 and 11 [7].

In contrast to the control group, the experimental group at gestational day 13 th in this study showed that the optic cup was well formed but it appeared to be shrunken with deeply stained pyknotic nuclei. These findings are supported by previous study done by [16] who stated that fetuses of dams fed $0.5 \mu \mathrm{g}$ zinc diet throughout gestation had microphthalmia of varying degree at term, ranging from microscopic remnants of ocular tissue to eyes with colobomata and extensive retinal folds. They added that invagination of the optic cup and closures of the choroid fissure were the processes that were adversely affected by developmental zinc deficiency. Moreover; they suggested that the microphthalmia and retinal folding seen in zinc-deficient fetuses at term probably resulted from lack of vitreous pressure due to non closure of the choroid fissure.

Furthermore, the present findings are in accordance with the previous research done by [16] who stated that examination of fetuses from zinc deficient dams, at day 12 and 14 of gestation revealed that invagination of the optic cup was often deficient and that closure of the choroid fissure did not occur, resulting in retinal folding visible at term and the lens remained at the placode stage in zinc deficient rat embryo. They elicited large numbers of necrotic cells that were seen in the diencephalic neuroepithelium near the optic cup. Moreover, they attributed the retardation of optic cup invagination and choroid fissure closure to the large number of necrotic cells seen in the diencephalic neuroepithelium adjacent to the optic vesicle suggesting that these necrotic cells might inhibit the normal optic cup formation. This is supported by other investigators who had shown that the embryonic neural epithelium was particularly prone to cell necrosis during periods of maternal zinc deficiency [17].
The current results are not in line with the earlier researches which demonstrated the relative lack of effect on ocular histogenesis in severely deficient fetuses at term (group of offspring of mothers fed a diet containing $0.5 \mathrm{tgZn}$ ) and in fetuses of mothers on the low-zinc diet (fed a diet containing $4.5 \mathrm{tgZn}$ group) near term, even among zinc-deficient fetuses with colobomata the folded retina often showed normal histogenesis [16]. This opinion may be explained by that dams fed zincdeficient diet throughout pregnancy were virtually anorexic during the last 3-4 days of pregnancy. This induced a catabolic state in the dam, freeing maternal tissue zinc which was then available to the fetus, as histogenesis is occurring during this period and fetuses appeared to be able to accumulate zinc in the eyes to a level similar to that of controls [18].

In addition, earlier studies noted that when zinc deficiency was instituted at parturition, eye opening was delayed but no morphological differences were noted among photoreceptor cells at weaning [19].

In this work, as compared with the control groups, the RPE of zinc-deficient rats of 15 th, $17^{\text {th }}$ and 19th days old embryos consistently contained apoptotic cells with vacuolated cytoplasm and rarified nuclei and the neuroblastic layer showed apparent decrease in thickness and less mitotic features while the ganglion cell layer revealed numerous deeply stained pyknotic nuclei in the 19 th gestational day. These findings are in harmony with earlier researches which demonstrated that in both groups of rats made zinc deficient either by treating them by zinc chelating agents, dithizone and 1,10-phenanthroline, or by feeding them a zinc-deficient diet similar findings were observed. There was a dense accumulation of osmophilic inclusion bodies in the retinal pigment epithelium and eventually degeneration of the retinal pigment epithelium and the photoreceptors outer segments [4].

By light microscopy in the present study, the retina of the newborn rat of the zinc deficient group showed that the retinal pigment epithelium and the neuroblastic layer contained some vacuolated cells with pyknotic nuclei. In addition to the pyknotic and vacuolated cells in 7 days-old zinc deficient albino rat retina; the inner segments of the photoreceptors revealed vacuolations. Moreover, Zinc deficient albino rat at the age of 15 and 21 days old revealed numerous deeply stained pyknotic nuclei and vacuolated cytoplasm in the outer nuclear layer, the inner nuclear layer and the ganglion cell layer These present findings are in line with 
previous study which showed that depletion of intracellular zinc may induce RPE cell apoptosis [20]. Moreover; the current results are in agreement with many other investigators who found that retinal degeneration in both zinc and taurine deficient group was in the form of generalized loss of the outer segments of the photoreceptors [19].

In harmony, previous studies demonstrated that retinal degeneration was observed to occur as a result of zinc or taurine depletion present throughout postnatal life and until 48-57 days of age in the rat. Morphologically, retinal degeneration was most pronounced in the rats deficient in both zinc and taurine [21].

Caspases played a pivotal role in developmental and pathologic death in the nervous system. Laboratory studies had revealed that apoptosis contributed to the pathogenesis of retinal cell death in retinitis pigmentosa, age-related macular degeneration, glaucoma, retinal detachment, and diabetic retinopathy, as well as pathologic myopia [22]. The deregulation of apoptosis was evident in pathological conditions such as cancer and neurodegenerative disorders [11].

The results of the present study showed intense positive caspase- 3 reaction in all layers of the treated rat retina. These findings were supported by earlier results of other researchers who stated that $\mathrm{Zn}$ is an important regulator of caspase-3, as well as an antioxidant, microtubule stabilizer, growth co-factor, and anti-inflammatory agent [23] In agreement, previous studies noted that depletion of available $\mathrm{Zn}$ in the apical cytoplasm of sheep and human airway epithelial cells leaded to rapid activation of caspase-3, culminating in apoptosis [24]. Moreover, other investigators demonstrated Caspase activation in the retina in a number of degenerative models of animals in which apoptosis was caused by ischemia, axotomy, excitotoxicity, and gene mutations [25]

Zinc is considered to be important to improve the level of antioxidant enzymes such as superoxide dismutase and catalase. These enzymes depend on zinc and iron in their metabolism. The alteration of the redox potential is thought to be closely associated with the changes in retinal cells of rats deficient in these micronutrients [26].

The current results may be explained by [27] who suggested that zinc deficiency causes decreased antioxidants in the retina and so it affects the taurine system in mammalian retinal cells.

\section{Conclusion:}

Data of this study showed that zinc has a role in the developing rat retinal cytoarchitecture and layering, and alterations in retinal maturation induced by gestational zinc deficiency could lead to retinal degeneration which may eventually end by visual impairment. Hence, zinc deficiency should be avoided during pregnancy to prevent most of the degenerative effects on the structure of the retina. Further researches should be done to support these findings and to determine the exact role of zinc in retinal maturation and the value of zinc supplementations during pregnancy.

\section{References}

1- STANDRING S.: "Gray's Anatomy, Eye". In: Standring S., Douglas R.H., Lawrenson J. G editors. Gray's Anatomy. 40th edition. Elsevier, pp., 686-708, 2016.

2- UGARTE M. and OSBORNE N.N.: "Recent advances in the understanding of the role of zinc in ocular tissues". Metallomics, 6: 189-200, 2014.

3- WALSH C.T., SANDSTEAD H.H., PRASAD, A.S., NEWBERNE, P.M. and FRAKER, P.J.: "Zinc: Health Effects and Research Priorities for the 1990s". Environmental Health Perspectives, Vol. 102 (Suppl 2): 5-46, 1994.

4- JULIEN S., BIESEMEIER A., KOKЮNOU D., EIBL O. and SCHRAERMEYER U.: "Zinc Deficiency Leads to Lipofuscin Accumulation in the Retinal Pigment Epithelium of Pigmented Rats". PLoS. One, Vol. 6: 1-8, 2011.

5- SAMUELSON D.A., LEWIS P.A., MACKAY E. and WHITLEY R.D.: "The influence of aging and low zinc nutrition on the choroid in the pig: II. The melanosome". Vet. Ophthalmol., 2: 35-45, 1999.

6- PAULL J.A. and FAIRBROTHER A.: "Vaginal lavage for pregnancy diagnosis in deer mice, Peromyscus maniculatus". J. Exp. Zool., 233: 143-149, 1985.

7- CHANG C., MANN D.E.Jr. and GAUTIERI R.F.: "Teratogenicity of Zinc Chloride, 1, 10-Phenanthroline, and a Zinc-1, 10-Phenanthroline Complex in Mice". Journal of Pharmaceutical Sciences, Vol. 66, No. 12, p. 1755-1758, 1977

8- EL-BADRY M.M., LENNE Y., HAS SAN F. Z., SALEH M.N.S. and ABDEL MALEK A.K.: "Developmental anatomy of the eyeball of the albio rat exemplified by ultrastructure and immunohistochemistry of the retina". Ph.D. thesis (Anatomy), Assiut University, 1991.

9- LOHMILLER J.J., and SWING S.P.: "Reproduction and breeding". In: Suckow MA, Weisbroth SH, Franklin CL (Ed.). The Laboratory Rat. 2 nd. Ed. New York, NY: Academic Press, pp. 147-162, 2006.

10-BANCROFT J.D. and GAMBLE M.: "Theory and practice of Histological Techniques". The 7 th ed. Philadelphia: Churchill Livingstone of Elsevier, pp. 172-186, 2013.

11-WU J., GORMAN A., ZHOU X., SANDRA C. and CHEN E.: "Involvement of caspase-3 in photoreceptor cell apoptosis induced by in vivo blue light exposure". Invest. Ophthalmol. Vis. Sci., 43: 3349-3354, 2002. 
12- COOK B. and ZELHOF A.C.: "Photoreceptors in evolution and disease". Nat. Genet., 40: 1275-1276, 2008.

13- ABOU EL-GHAIT A.T., RATEB A., MAHMOUD F.Y. and GALAL O.: "Effect of experimentally induced hypothyroidism during pregnancy and lactation on the retina of juvenile and adult albino rats and the possible role of thyroid hormone supplementation", Egypt J. Histol., 34: 28-45, 2011.

14- EL-GOHARI K.M.A., BAHEI-ELDIN I.A., HABIB E.M.K., SAAD S.A., RADY, H.Y.S. and SAID A.M.A.: "Neuroprotection of the rat's retinal ganglion cells against glutamate-induced toxicity". Journal of the Egyptian Ophthalmological. Society, 109: 135-144, 2016.

15- National Research Council (US) Subcommittee on Laboratory Animal Nutrition: Nutrient Requirements of Laboratory Animals. Fourth Revised Edition, Washington (DC): National Academies Press (US), P 36, 1995.

16- ROGERS J.M. and HURLEY L.S.: "Effects of zinc deficiency on morphogenesis of the fetal rat eye". Development, 99: 231-238, 1987.

17- TERRIN G., BERNI CANANI R., DI CHIARA M., PIETRAVALLE A., ALEANDRI V., CONTE F. and de CURTIS M.: Zinc in early life: A key element in the fetus and preterm neonate. Nutrients, 7: 10427-10446, 2015.

18-EMMERT J.L. and BAKER D.H.: Zinc Stores in Chickens Delay the Onset of Zinc Deficiency Symptoms. Poultry Science, Volume 74, Issue 6, Pages 1011-1021, 1995.

19- GOTTSCHALL-PASS K.T., GRAHN B.H., GORECKI D.K.J. and PATERSON P.G.: "Oscillatory potentials and light microscopic changes demonstrate an interaction between zinc and taurine in the developing rat retina". J. Nutr., 127: 1206-1213, 1997.
20- HYUN H.J., SOHN J.H., HA D.W., AHN Y.H., KOH J.Y. and YOON Y.H.: "Depletion of intracellular zinc and copper with TPEN results in apoptosis of cultured human retinal pigment epithelial cells". Invest. Ophthalmol. Vis. Sci., 42: 460-5, 2001.

21- PATERSON P.G., GRAHN B.H., GOTTSCHALL-PASS K.T., GORECKI D.K.J. and SEMPLE H.A.: "Postnata deficiencies of zinc and taurine alter electroretinograms, oscillatory potentials and morphology of the rat retina". Nutri. Neurosci., 2: 175-189, 1999.

22- NICKELLS R.W.: "Apoptosis of retinal ganglion cells in glaucoma: An update of the molecular pathways involved in cell death". Surv. Ophthalmol., 43 (Suppl): S151-S161, 1999.

23- DANIAL N.N. and KORSMEYER, S.J.: "Cell death: critical control points". Cell. Jan., 23, 116 (2): 205-19, 2004.

24- VALLEE B.L. and FALCHUK K.H.: "The biochemical basis of zinc physiology". Physiol. Rev., 73: 79-118, 1993.

25- TRUONG-TRAN A.Q., CARTER J., RUFFIN R.E. and ZALEWSKI P.D.: "The role of zinc in caspase activation and apoptotic cell death". Biometals, 14: 315-330, 2001.

26- MARGERET A. AZIZ, ANHAR M. GOMAA, LAILA K. HANAFY and FATMA ABD EL-HADY SOLIMAN: "Interaction between micronutrients; vitamin a, zinc and iron in the eye (biochemical and histological studies)". Bull. Egypt. Soc. Physiol. Sci., 26 (2): 47-46.

27- MÁRQUEZ GARCÍA A., SALAZAR V. and LIMA L.: "Effect of Extracellular Zinc Chelator on Rat Retinal Ganglion Cell Number, and Taurine and Zinc Transporters in These Cells". Acta. biol. Colomb., Vol. 22 (2): 137148, 2017. 


\section{تأثير نقص الزنك خلال الحمل على تطور الشبكية في الفأر الأبيض قبل وبعد الولادة الزمل فلورال}

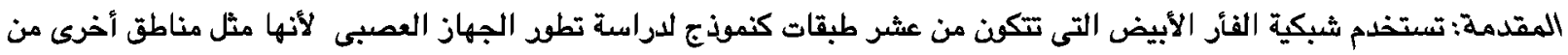

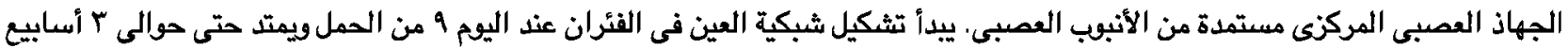
بعد الولادة.

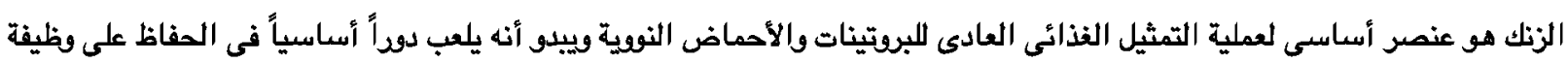

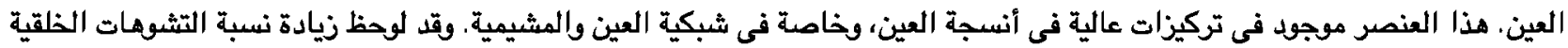

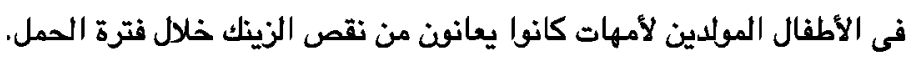

الهدف من البحث: تهدف هذه الدراسة إلى دراسة تأثير نقص الزنك فى الأمهات خلال فترة الحمل على نمو الثبكية فى الفئران ليضضاء.

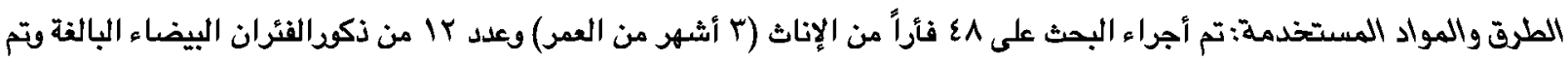

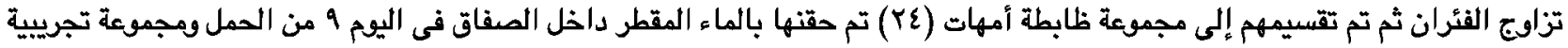

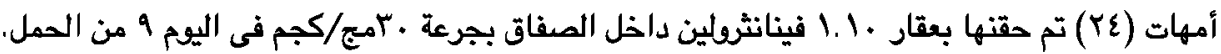

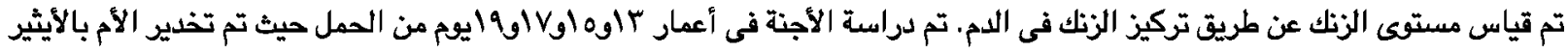

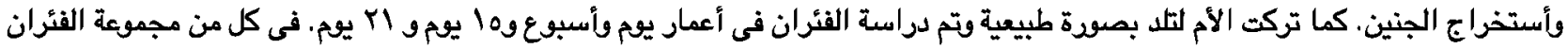

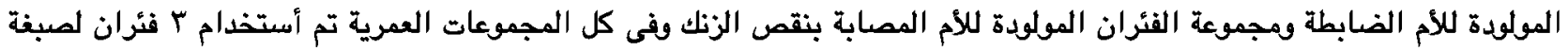

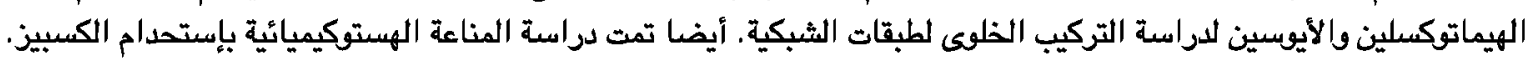

النتائج: أظهر الفحص المجهرى للمجموعة التجريبية فى يوم الحمل با في هذه الدراسة أنكماش واضح من حويصلة العدسة. تم تشكيل

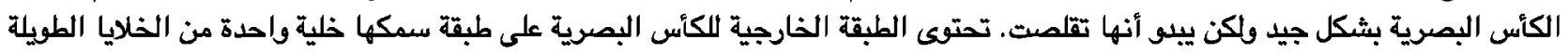

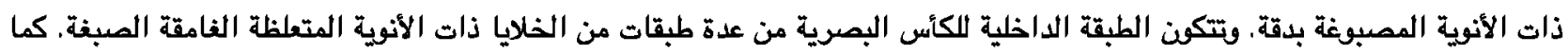

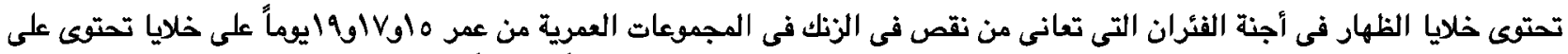

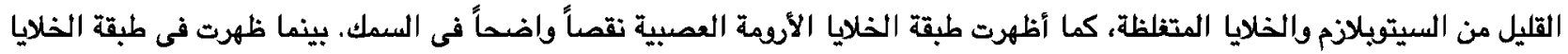

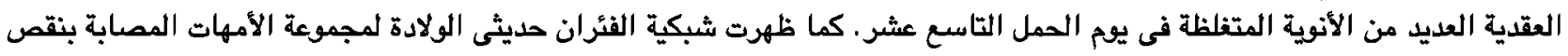

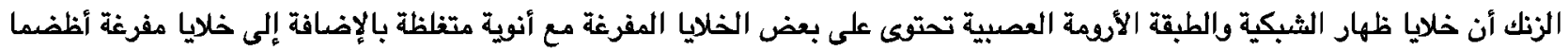

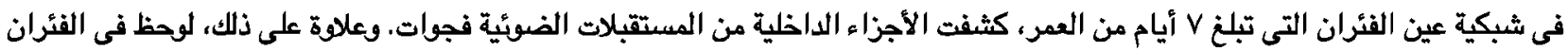

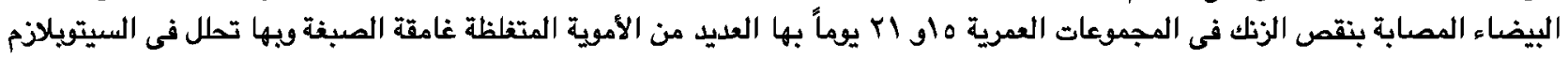

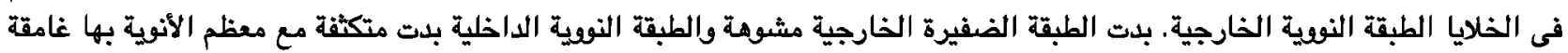

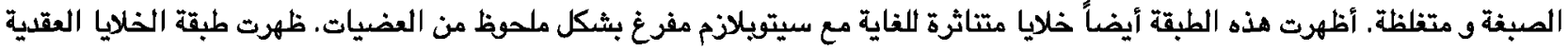

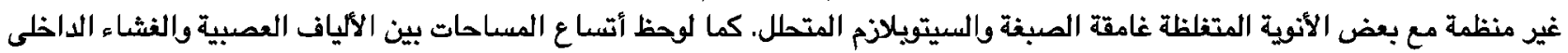

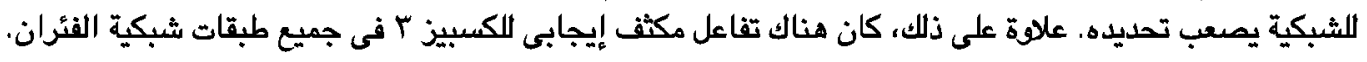

الخلاصة: أوضحت هذه الدراسة أن نقص الزنك فى الأم يسبب تغيراً فى تطود شبكية الفئران البيضاء. من المستحسن أن يكن هناك رقابة صارمة على مستوى الزتلك أثثاء الحمل. 